\title{
Atitudes e crenças sobre o uso de tu e você na variedade de Rio Branco
}

\section{Attitudes and beliefs about the use of tu and você in the Rio Branco variety}

\author{
Roberto Gomes Camacho* \\ Marinete Rodrigues da Silva**
}

\section{RESUMO}

A questão da avaliação subjetiva de variantes se assenta teoricamente no levantamento de crenças e atitudes a respeito de algum fenômeno variável próprio de línguas ou variedades dialetais em termos de atribuição de valores de prestígio e de estigma. Nesse âmbito, um fenômeno particularmente variável na variedade acriana de Rio Branco é o uso das formas de referência ao interlocutor. Em razão disso, o principal objetivo deste artigo é o de aplicar testes de avaliação de atitudes e crenças aos falantes dessa comunidade de fala para avaliar se há valores sociais de estigma e prestígio relacionado aos pronomes tu e você. Os resultados mostram que (i), por um lado, os dados obtidos com base na dimensão do poder apontaram para a existência de um valor de prestígio atribuído ao pronome você, que se origina, de modo geral, dos julgadores de grau superior de escolaridade; (ii) por outro lado, os dados analisados com base na dimensão de solidariedade apontaram para uma aceitação maior de todos os grupos de avaliadores por $t u$.

Palavras-chave: Reação subjetiva; testes de atitudes; testes de crenças; pronomes de segunda pessoa.

Recebido em 1 de março de 2021.

Aceito em 23 de abril de 2021.

DOI: http://doi.org/10.18364/rc.2022n62.495

* Universidade Estadual Paulista, roberto.camacho@unesp.br, http://orcid.org/0000-0002-8897-7953

** Universidade Federal do Acre, neety2303@gmail.com, http://orcid.org/0000-0001-5242-8509

Confluência. Rio de Janeiro: Liceu Literário Português, n. 62, p. 81-121, jan.-jun. 2022 


\section{ABSTRACT}

The issue of subjective evaluation of variants is theoretically based on the survey of beliefs and attitudes about some variable phenomenon specific to languages or dialectal varieties in terms of assigning values of prestige and stigma. In this context, a particularly variable phenomenon in the Rio Branco variety is the use of forms of reference to the interlocutor. For this reason, this paper's main objective is to apply tests to speakers of this speech community to assess whether there are social values of stigma and prestige related to use of the pronouns $t u$ and você. The results show that (i), on the one hand, the analysis obtained from the dimension of power pointed to the existence of a value of prestige assigned to the pronoun você departing, in general, from judges with higher education levels; (ii) on the other hand, the analysis obtained from the dimension of solidarity pointed to a greater acceptance of all groups of judges for the use of $t u$.

Keywords: Subjective reaction; test of attitudes; test of beliefs; second person pronoun.

\section{Palavras iniciais}

Uma consequência da supervalorização institucionalizada da normapadrão são as reações dos falantes a qualquer uso que fuja dela, que podem, na maioria das vezes, ativar preconceitos sociais latentes. Esse tipo de reação subjetiva pode ser mensurada mediante atitudes e crenças que o falante manifesta indiretamente em relação a um fenômeno variável, potencialmente sujeito a valores de prestígio e estigma. A abordagem das atitudes e crenças linguísticas remonta à década de 60, quando Lambert et al. (1960), em estudo pioneiro, investigaram a avaliação de jovens canadenses falantes de francês e de inglês em relação a sua própria língua. $\mathrm{O}$ experimento de Lambert e associados ficou conhecido como matched guise technique, ou "técnica dos falsos pares" em razão de suscitar a crença no avaliador de que as gravações ouvidas provêm de indivíduos diferentes quando na verdade são enunciados produzidos por um único e mesmo falante.

Labov (2008 [1972]) também tem parte relevante nesse pioneirismo. Ao investigar a comunidade da ilha Martha's Vineyard em relação à centralização dos ditongos /aj/ e /aw/, o autor aplicou um questionário lexical 
para o levantamento crenças ou juízos de valor. Também no estudo realizado sobre a variedade de Nova Iorque, Labov (2008 [1972]) fez uso da técnica dos falsos pares de Lambert et al. (1960), que lhe permitiu deduzir que a presença ou ausência de [.t] em posição pós-vocálica está relacionada a questões de atitude. Para Labov (2008 [1972]), a técnica dos falsos pares permite que os avaliadores demonstrem inconscientemente suas atitudes e julgamentos sociais em relação à variação linguística, fazendo emergirem muitas vezes atitudes sociais extremamente uniformes em relação à língua da comunidade de fala. Essa uniformidade nas reações subjetivas ocorreu também no estudo de Lambert et al. (1960), que apontou para a existência de uma atitude negativa para com o francês canadense tanto na comunidade anglófona como na francófona do Quebec.

$\mathrm{Na}$ linguística brasileira, destacam-se os trabalhos de Mendes e Oushiro (2012), Oushiro (2014) e Vassoler e Camacho (2016). Mendes e Oushiro (2012) se organizaram em torno da constituição de uma amostra da fala paulistana, que permitiu descobrir qual é o significado de "falar como paulistano" mediante o levantamento das principais variantes linguísticas que o identificam. Com base nessa amostra, Oushiro (2014) analisou as associações entre a percepção de identidades sociais em relação a quatro variáveis sociolinguísticas. Após caracterizar cada uma das variáveis enfocadas com base nos dados obtidos na análise quantitativa e discutir seu encaixamento linguístico e social, bem como seu status na comunidade, Oushiro (2014) desenvolveu uma análise das variantes retroflexa e tepe com base na técnica dos falsos pares (LAMBERT et al., 1960), fenômeno analisado também por Vassoler e Camacho (2016), que investigaram também a pronúncia retroflexa do rótico em coda silábica, uma variante regularmente usada pelos falantes de outro dialeto social, a chamada "variedade caipira", que inclui a região de São José do Rio Preto.

Para examinar em que medida esse traço característico é também estigmatizado na variedade rio-pretense, Vassoler e Camacho (2016) avaliaram o grau de prestígio ou de estigmatização dessa variante em comparação a 
outras duas pronúncias possíveis: o tepe alveolar e a fricativa velar, no contexto seguinte a /a/, /i/ e /u/. O procedimento metodológico incluiu uma gravação de 27 enunciados contendo essas três realizações à qual se aplicou, em seguida, testes de atitudes e de crenças linguísticas a dois grupos de participantes com ensino fundamental, um da rede pública e outro da rede particular, e um grupo de participantes com ensino superior. Nos resultados do teste de atitudes, os participantes com ensino superior atribuíram notas mais altas que os participantes do ensino fundamental à pronúncia de tepe em todas as escalas avaliadas. No geral, os resultados mostraram que, apesar de a retroflexa constituir um traço identificador da variedade caipira, é ao tepe que os participantes atribuem maior grau de prestígio.

Tanto o trabalho de Labov (2008 [1972]) quanto o de Oushiro (2014) e o de Vassoler e Camacho (2016) medem as atitudes como indícios de variáveis estáveis ou em processo de mudança linguística. No entanto, o estudo de reações subjetivas pode estar voltado para o desvelamento de atitudes sobre o sentimento de prestígio ou de estigma aplicado a línguas em situação bilíngue, como o estudo pioneiro de Lambert et al (1960), ou para valores de prestígio em relação ao ensino da língua, como o estudo de Santos (1996), Cyranka (2007), Fiamengui (2017) e Camacho e Fiamengui (2019).

Santos (1996) entende que, nos estudos linguísticos, o componente afetivo, que lida com avaliações positivas, negativas ou neutras, torna-se acessível por meio da aplicação de testes envolvendo um estímulo a uma reação do respondente, que deve julgar se uma propriedade é favorável, desfavorável ou neutra. Em seu estudo, Santos (1996) supõe que a escola assume um sistema de crenças ligado diretamente a sua própria formação ideológica que, dentre outros aspectos, inclui a imagem que ela tem da língua. Essas crenças podem não se manifestar explicitamente, mas é certo que exercem alguma influência sobre o ensino da língua padrão na escola.

Cyranka (2007) aplicou um teste de atitudes linguísticas a alunos de oitava série do ensino fundamental de cinco escolas públicas do Município de Juiz de Fora com a finalidade de examinar o julgamento deles em relação a 
três variedades linguísticas, detectadas no contínuo rural-urbano (BORTONIRICARDO, 2005). O teste de atitudes mostrou uma identificação de todos os alunos com a variedade rurbana, intermediária entre a rural e a urbana. A autora aplicou também um teste de crenças aos mesmos alunos, a professores da mesma escola e a formandos de Letras da UFJF, cujos resultados apontam para a existência de um conflito dos alunos entre a aprovação de sua variedade linguística, detectada no teste de atitudes, e a declaração de que não sabem escrever, nem falar bem, detectada no teste de crenças. $\mathrm{O}$ sentimento ativado por essas crenças é o de baixa autoestima e o de preconceito linguístico às vezes até mesmo contra seu próprio registro falado, que consideram menos correto do que a escrita normativa.

Fiamengui (2017), por seu lado, investigou a interação entre crenças e preconceitos no contexto multilíngue na fronteira entre o Brasil e o Paraguai, mais especificamente a fronteira seca entre Ponta Porã e Juan Pedro Caballero com base na relação entre o espanhol, o guarani e o português. Camacho e Fiamengui (2019) trataram da mesma situação multilíngue em detrimento do guarani em relação ao processo de alfabetização, que entra seriamente em conflito com o grau de letramento possível de que dispõem os alunos paraguaios, um caso exemplar de cumprimento de uma premissa teórica levantada por Street (2007): o caráter dominante de uma cultura, que é, nesse âmbito, o grau de letramento em português ou em espanhol de falantes que têm o guarani como L1.

A questão da avaliação subjetiva, seja de variantes, seja de variedades, seja de línguas, que, como se vê, assenta-se no levantamento de crenças e atitudes, pode voltar-se diretamente ao exame do julgamento a respeito de algum fenômeno variável próprio de línguas ou variedades dialetais em termos de atribuição de valores de prestígio e de estigma. Nesse âmbito, um fenômeno particularmente variável na variedade acriana de Rio Branco é o uso das formas de referência ao interlocutor, como mostram (1) e (2). 
(1) Se tu fizer uma falta... tu não tira na bola bate no jogado, é falta .... (Banco de dados GELAC. Ent. 12) ${ }^{1}$

(2) É que nem você falou né, é um desrespeito, deveria ter mais respeito não sei. (Banco de dados GELAC. Ent. 27)

Pode-se interpretar uma variedade linguística como um traço definidor de identidade e, desse modo, qualquer tipo de crença ou de atitude em relação a um grupo com certa identidade social constitui, na realidade, uma reação à variedade usada por esse grupo ou aos indivíduos usuários dessa variedade, uma vez que as normas e as marcas culturais se sedimentam com base no uso da língua, atualizado na fala de cada indivíduo (AGUILERA, 2008 p. 317).

Nesse sentido, as crenças têm um papel muito importante a desempenhar como instrumento auxiliar do pesquisador para aferir o grau de consciência linguística em diversas situações sociais, como a de alternância de código e a de bilinguismo, sem descuidar da questão do aprendizado de uma ou mais línguas.

Com base nesses pressupostos, propomos como objetivo deste trabalho analisar as atitudes e crenças apresentadas nas avaliações subjetivas dos falantes da variedade rio-branquense do Acre em relação às formas pronominais $t u$ e você, para responder às seguintes perguntas: (i) é possível atribuir à forma $t u$ um valor de prestígio encoberto ${ }^{2}$, que se pode detectar em relações interpessoais de natureza informal, em oposição à forma você, a mais prestigiosa por ser exigida em situações formais? (ii) As atitudes de prestígio, que emergem da reação subjetiva, estão correlacionadas a diferenças marcadas de uso, em situações de grau maior, ou de menor, de informalidade?

1 As informações entre parênteses indicam a origem da amostra e o número da entrevista respectiva; Todos os trechos citados foram retirados do Corpus GELAC- Grupo de Pesquisa Ecossistema linguístico do Acre.

2 Se há, por um lado, pressões sociais que promovem a variedade padrão, deve haver também pressões contrárias favorecendo a variedade local e informal. No entanto, se assim for, essas pressões contrárias devem ser tácitas e não conscientes, porque elas não são fáceis de identificar, diferentemente das forças que favorecem o padrão, que são cristalinamente claras (CHAMBERS, 1996, p. 221) 
Para responder a essas perguntas, o trabalho se organiza da seguinte maneira: na seção 1, adiantam-se os fundamentos teóricos que nortearão a pesquisa; na seção 2, dá-se continuidade às premissas teóricas para se tratar, mais especificamente, do universo de investigação e dos procedimentos metodológicos; nas seções 3 e 4, trata-se de responder mais especificamente às perguntas de pesquisa: na seção 3 , apresenta-se a análise dos resultados do teste de atitudes e, na seção 4, os resultados do teste de crenças. Finalizam este trabalho as Considerações Finais, em que se faz um balanço dos principais resultados, estendendo-o às implicações teóricas e às generalizações possíveis.

\section{Afinando os instrumentos: o suporte teórico}

Como os julgamentos sociais podem situar-se abaixo ou acima da consciência do falante, Labov (2008 [1972]) distingue três tipos de categorias aplicadas a fenômenos variáveis: indicadores, marcadores e estereótipos. Os indicadores, cuja relevância social se situa abaixo do nível da consciência, são traços pouco susceptíveis à pressão avaliativa; ao se afigurarem como processos variáveis submetidos a uma mudança, ainda no início da implementação, os indicadores consistem em variáveis ainda não sujeitas à motivação estilística, mas apenas à social. Já os marcadores implicam diferenças de natureza social e estilística, que emergem quando a mudança linguística já se encontra numa fase mais adiantada de implementação.

Como traços social e estilisticamente estratificados, os marcadores estão especialmente sujeitos a testes de avaliação, como o que se pretende desenvolver aqui para a variação $t u$ e você na variedade rio-branquense. Entendem Coelho e Vieira-Pinto (2018) que essas variantes são de fato exemplos de marcadores e, embora não constituam formas estigmatizadas, estão correlacionadas a motivações derivadas do grau de intimidade entre os falantes.

Por fim, os estereótipos constituem traços socialmente marcados, cuja relevância social se situa acima do nível da consciência, e que podem, assim, conduzir a um rápido processo de mudança, que se completa mediante a extinção 
da forma estigmatizada. Segundo Labov, os estereótipos produzem uma visão pouco sistemática da estrutura linguística. A correção social explícita da fala é extremamente irregular por focalizar os itens lexicais mais frequentes, ao passo que o curso real da mudança linguística, que produz as formas marcadas dessas variáveis, é altamente sistemático e regular (LABOV, 2008 [1972], p. 287).

Falantes que aspiram à mobilidade social ascendente são extremamente sensíveis aos valores simbólicos de prestígio identificados na fala. Labov (1966) mostra que a pronúncia da consoante inicial de palavras como this e there, representada como a variável (dh), é fortemente correlacionada à estratificação social dos falantes. A variante de prestígio, a interdental [ð], é mais suscetível de ser produzida por falantes de classe média e média alta, enquanto falantes da classe operária tendem a usar a forma estigmatizada [d]. Ao comparar um grupo de falantes com aspiração à mobilidade social ascendente a um grupo de falantes com afiliação social estável, Labov (1966) afirma que a fala do grupo em processo de ascensão social se ajusta à do grupo alvo de suas aspirações, justamente o que se situa no patamar mais alto da escala socioeconômica.

Esses elementos estáveis, que representam posições sociais marcadas, podem constituir um pequeno número de fenômenos situados acima do nível da consciência social explícita, que atuam, portanto, como estereótipos. Em relação à variável (ing) alguém pode dizer que o falante "drop his g's" ("engole o g") ou ser um daqueles "dese, dem and dose guys" ("aqueles caras que falam dese, dem e dose") ao comparar a variante [d], estigmatizada com a alternante [ð] de prestígio em these, them e those (LABOV, 2008 [1972], p. 287)

Outras pesquisas de Labov (2008 [1972]) incidem sobre a realização do [Ł] pós-vocálico seguido ou não de consoante na fala de Nova Iorque; nesse âmbito, uma importante descoberta é a de que falantes que, no uso, promovem o apagamento de [.] quase categoricamente no registro informal, tendem, nos testes de avaliação subjetiva, a atribuírem valor de prestígio à realização desse segmento.

O procedimento metodológico empregado para a análise das normas interiorizadas pelos falantes é a aplicação de testes que medem a atitude subjetiva 
deles em relação às variantes em análise. Como já mencionado, essas avaliações são empiricamente detectáveis somente por via indireta, justamente por consistirem em valores situados abaixo do nível da percepção consciente. Somente estão acima do nível da percepção consciente os estereótipos, que constituem, em geral, fontes de preconceito social, como o é dizer que o paranaense enuncia a frase "leite quente dá dor de dente" com todas as vogais anteriores em posição final no espectro médio da articulação (CAMACHO, 2013).

No caso específico de seu experimento pioneiro, Lambert et al. (1960) gravaram quatro falantes bilíngues, que leram um mesmo texto em inglês e francês. Duas outras gravações foram incluídas a essas oito como procedimento de controle. As gravações foram apresentadas posteriormente a estudantes de duas universidades de Montreal, distribuídos entre francófonos e anglófonos. Para cada um dos dez estímulos, os participantes deveriam julgar os falantes em relação a quatorze características pessoais, organizadas em escalas de seis pontos, na suposição de que as vozes ouvidas provinham sempre de diferentes indivíduos.

Esse método indireto passou depois por diversas alterações, especialmente em relação à escala de avaliação. A alteração mais conhecida, nesse domínio, segundo Cyranka (2007, p. 27), denominada "técnica do diferencial semântico", consiste na construção de uma série de escalas bipolares de sete pontos, com adjetivos de valores opostos colocados nas extremidades do continuum. A construção de um conjunto de escalas desse tipo propicia a obtenção de uma classificação múltipla de atitudes em relação a um estímulo. Como as respostas avaliativas são representadas por números nos traços da escala, é possível chegar a um cálculo descritivo-demonstrativo das reações subjetivas dos falantes em relação as amostras de fala e, consequentemente, aos dialetos dos sujeitos avaliados (CYRANKA, 2007).

Os testes de atitudes são, portanto, planejados para permitir a emergência de dimensões em escalas avaliativas, emanadas da subjetividade de ouvintes-julgadores em relação ao valor social de variantes, de variedades dialetais e mesmo dos indivíduos que as falam. Esses julgamentos propiciam 
a depreensão de valores e significados relevantes para a identificação de valores de prestígio ou estigma social.

Uma situação de pesquisa, que envolva julgamento auditivo de realizações de uma variável, implica, portanto, a existência de uma amostra previamente gravada por falantes nativos da variedade em pauta, que venha a servir de estímulo, depois, para a aplicação do teste de avaliação subjetiva, situação em que se toca a gravação para a audição e posterior julgamento dos participantes da pesquisa.

Em geral, os testes de atitudes linguísticas mostram que um locutor ouvido na gravação que emprega uma língua ou variedade linguística de prestígio atrai uma percepção favorável dos julgadores em relação a parâmetros como inteligência, competência, ambição, segurança, sucesso educacional e ocupacional. Decorre dessa percepção positiva o princípio de que a variedade padrão se associa à dimensão de poder, "status" e controle social.

Chambers (1996), todavia, sinaliza a existência de duas dimensões na avaliação subjetiva: uma, que ele denomina "orientação para o prestígio", inclui qualidades de inteligência, educação, ambição, riqueza, sucesso e conquista, para as quais os julgadores atribuem as notas avaliativas mais elevadas aos falantes da variedade padrão. A outra dimensão, "orientada para a solidariedade", inclui qualidades como gentileza, amabilidade, amizade, bondade e confiança, para as quais os sujeitos julgadores atribuem notas avaliativas mais elevadas aos falantes de variedades não padrão.

\section{Afinando os instrumentos: procedimentos metodológicos}

Em face das premissas teóricas apresentadas na seção precedente, a preparação do teste de atitudes requereu o uso de amostras gravadas de fala do corpus analisado. Os estímulos foram, portanto, organizados com base em trechos de gravações com seis falantes, estratificados por sexo/gênero, escolaridade e classe social. Os trechos recortados da gravação transcrita são apresentados de (3-8). 


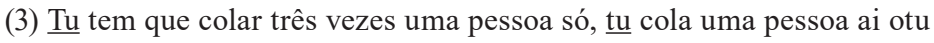
amigo tem que discolar ele. Ai tu vai colar essa mesma pessoa três vezes é a manja. (Corpus GELAC - Entr. 13)

(4) e você não vê isso, você vê pessoas que só querem visa o lucro, e tão aqui querendo estuda só pá se rico. (Corpus GELAC - Entr. 47)

(5) Aí o estudo la... na primeira série tu tá estudando inglês; na pública tu não tem isso. (Corpus GELAC - Entr.96)

(6) Cozinha u macarrão, dependi Du que você vai colocar, ou carne moída ou salsicha...cozinha a carne e a salsicha, mistura com o macarrão e os ingredientes, sal a gosto o que quiser e fica a macarronado do jeito que quiser. (Corpus GELAC - Entr. 19)

(7) $\underline{\mathrm{Tu}}$ que qui eu seja bem sincero? (Corpus GELAC - Entr. 47)

(8) si você pega o mapa do nosso bairro você vai, vê qui a Assembléia ta dento do nosso mapa, qui nu existi distância pó palácio. (Corpus GELAC - Entr. 62)

O procedimento envolveu a participação de 30 sujeitos avaliadores, 10 de cada grau de escolaridade (fundamental, médio e superior), separados por sexo/gênero ( 5 homens e 5 mulheres). O critério de agrupamento por grau de escolaridade se assenta no reconhecimento amplo de uma correlação diretamente proporcional entre escolaridade e conhecimento da norma que rege o uso; a separação por sexo/gênero dá equilíbrio à grade de informantes, além de fornecer um critério adicional de avaliação de valores de prestígio e estigma. Para cada estímulo, os participantes responderam a um teste de atitudes e a um teste de crenças, aplicados nessa ordem por representarem um grau crescente de conscientização dos valores sociais vinculados às variantes.

O teste de avaliação de atitudes, disposto no Quadro 1, foi elaborado, com base na proposta de Cyranka (2007), mediante o uso da técnica do diferencial semântico, que, conforme já mencionado, consiste na construção de uma série de escalas bipolares de sete pontos, com adjetivos de valores opostos colocados na extremidade do continuum. 
Quadro 1. Ficha de avaliação do teste de atitudes

\section{TESTE DE ATITUDES}

Nome:

Sexo: Idade:

Escolaridade:

\section{QUESTIONÁRIO I}

Quando ouvimos a voz de uma pessoa, sem vê-la, formamos impressões sobre ela. É o que provavelmente acontecerá com você quando ouvir os trechos gravados que lhe serão apresentados agora. São três gravações, cada uma delas trazendo a voz de pessoas diferentes. Depois de ouvir cada um desses pequenos trechos, indique a impressão que lhe causou, a partir das questões abaixo.

A sua resposta deve ser dada da seguinte maneira: atribua uma nota variando de 7 a 1, em relação às qualidades expressas pelos adjetivos que estão relacionados. Você tem seis adjetivos, cada um deles seguido de sete traços. Cada traço corresponde a uma nota.

Quanto mais próxima do adjetivo, maior será a nota. Assim, se você atribuir a um dos falantes a nota mais alta (7), em relação ao adjetivo inteligente, você deve colocá-la no quadrado próximo a esse adjetivo; se você atribuir a nota imediatamente inferior (6), deve colocá-la no segundo quadrado, e assim sucessivamente, até a menor (1), que deverá ser colocada, se for o caso, no último quadrado. Isso em relação a cada um dos adjetivos.

Você vai ouvir uma gravação de cada vez. Depois de cada uma delas, vamos lhe dar um tempo para você colocar as notas nos quadrados. Só então ouvirá a gravação seguinte para atribuir as notas, e assim sucessivamente.

Para você, essa pessoa parece...

(Escolha uma opção em cada linha)

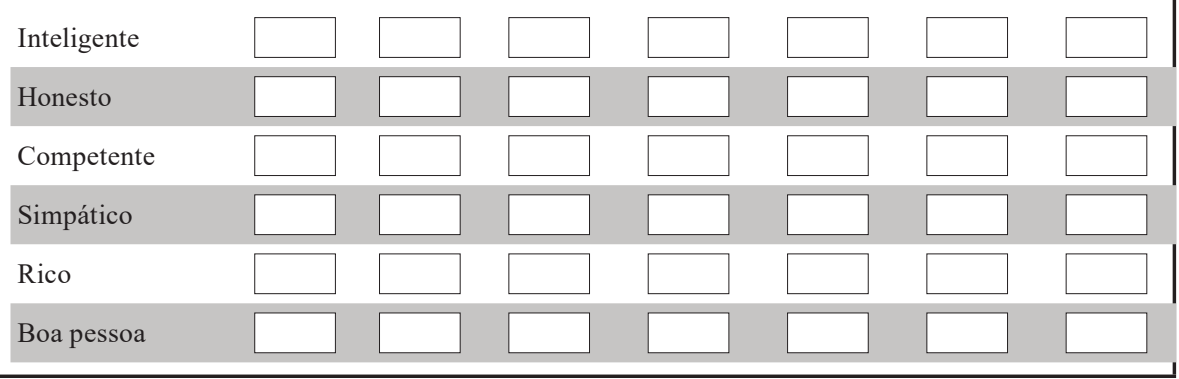

Fonte: SILVA, 2019, p. 139.

Organizou-se o teste de atitudes em função de seis atributos que remetem a valores de poder e solidariedade. A dimensão de poder foi representada pelos atributos "inteligente", "competente" e "rico", enquanto a dimensão de solidariedade, pelos atributos "honesto", "simpático" e "boa pessoa". Os

Confluência. Rio de Janeiro: Liceu Literário Português, n. 62, p. 81-121, jan.-jun. 2022 
participantes receberam a instrução de que ouviriam três estímulos, contendo um uso dos pronomes tu e você, e que deveriam escolher para cada qualificação uma nota com base na impressão que o locutor lhe teria causado pela escolha de uma ou outra forma de referência à segunda pessoa. Em seguida aplicou-se o teste de crenças, conforme mostra o Quadro 2.

Quadro 2. Ficha de avaliação do teste de Crenças

\section{QUESTIONÁRIO II}

Marque com um $(\mathrm{X})$ o falante analisado:

( ) Falante I ( ) Falante II ( ) Falante III

1. Você acha que esta pessoa está em que faixa etária?
( ) Na adolescência
( ) 20 e poucos anos
( ) Por volta de 30 anos
( ) Por volta de 40 anos
( ) por volta de 50 anos

2. Você acha que esta pessoa estudou...
( ) até o ensino fundamental
( ) até o ensino médio
( ) até o curso superior

3. Você acha que esta pessoa pertence à...
( ) Classe baixa
( ) Classe média
( ) Classe alta

4. Do que você ouviu, você acha que essa pessoa...

Fala Bem? Sim ( ) Não ( )

Essa forma de uso é adequada? Sim ( ) Não ( )

Essa pessoa mora no perímetro urbano de Rio Branco? Sim ( ) Não ( )

5. Qual das duas perguntas é mais adequada para você?
a) Você qué(r) um sorvete?
b) Tu qué(r) um sorvete?

6. Qual das duas perguntas você usa mais?

a) Você qué(r) um sorvete?

b) Tu qué(r) um sorvete?

Fonte: SILVA, 2019, p. 140. 
Como no teste de atitudes, cada participante recebeu um questionário, composto por três perguntas fechadas, mas com duas alternativas possíveis de respostas sim e não, e duas perguntas igualmente fechadas, mas com duas alternativas para avaliar um possível sentimento de insegurança linguística do avaliador.

O teste de atitudes solicita uma avaliação indireta, apelando, portanto. para percepções sobre a variável situadas abaixo do nível de consciência dos participantes envolvidos (CYRANKA, 2007). Já o teste de crenças, composto por questões diretas, recebe também respostas diretas do tipo "falso-ouverdadeiro", "sim-ou-não", relacionadas a um nível mais consciente de percepção, que remete, portanto, às crenças e aos preconceitos dos participantes de acordo com o imaginário social de que compartilham e da identidade que perfilam na comunidade de fala. Na visão de Conner et al. (2007, p. 1728), as atitudes implícitas, aqui entendidas como atitudes propriamente ditas, evocam respostas automáticas, espontâneas, subentendidas ou não controladas, enquanto atitudes explícitas, aqui entendidas como crenças, evocam respostas não automáticas, deliberadas ou controladas.

Os dados coletados nos testes foram submetidos ao programa Statistical Package for Social Sciences (STEVENS, 2015), que permite organizar e resumir bases de dados de trabalhos estatísticos, tornando-os quantitativamente comensuráveis. A análise estatística do teste de atitudes foi conduzida pela Análise de Variância (Anova, do inglês Analysis of Variance), que, segundo Cyranka (2007) e Vassoler e Camacho (2016), é uma ferramenta destinada à comparação de vários grupos envolvidos; no caso desta pesquisa, são os três grupos de participantes com diferentes perfis escolares, tendo como variáveis dependentes os valores de 1 a 7 para cada fator analisado (inteligente, competente, rico, honesto, simpático, boa pessoa). O emprego desse teste tem por objetivo confirmar ou refutar estatisticamente as seguintes hipóteses estatísticas: hipótese nula (H0): não existe associação entre as proporções relativas do conteúdo das respostas e a natureza social dos avaliadores; hipótese inicial (H1): existe 
associação entre as proporções relativas do conteúdo das respostas e a natureza social dos avaliadores.

O fator independente considerado na análise foi o grau de escolaridade do participante avaliador, ou seja ensino fundamental, médio ou superior. Utilizou-se a correção de Bonferroni como teste post-hoc para ajustar as medidas de significância às múltiplas comparações ${ }^{3}$. Para ambos os testes, o limite do nível de significância foi estabelecido em $\mathrm{p}$ igual ou menor que 0,05 .

Num teste realizado em um nível de confiança de 0,95 , deve-se observar se o valor de $p$ é maior ou menor que 0,05 . Quando o p-valor é maior que 0,05 , pode-se rejeitar a hipótese inicial. Consequentemente, a média de um grupo será significativamente diferente das médias dos outros. Do mesmo modo, se o p-valor é igual ou menor que 0,05 , não se pode rejeitar a hipótese inicial, embora seja possível admitir que as diferenças sejam obra do acaso. Se a hipótese inicial for rejeitada, ou seja, se pelo menos uma das médias testadas for diferente, aplica-se o teste Post Hoc de Tukey ${ }^{4}$, para verificar as médias que são estatisticamente diferentes.

3 Conforme entendem Vassoler e Camacho (2016), usa-se o teste post-hoc após o desenvolvimento da análise Anova com a finalidade de verificar que médias são estatisticamente diferentes. Como o Anova consiste em múltiplas comparações, é necessário proceder ao ajuste de medidas de probabilidades para se aumentarem as chances de emergir uma diferença significativa. A correção de Bonferroni consiste basicamente na divisão dos valores de significância observados inicialmente pelo número de comparações realizadas.

4 O Teste de Tukey (ou procedimento de Tukey), também chamado de "teste de Diferença Significativa Honesta (HSD) de Tukey", é um teste post-hoc baseado na distribuição de intervalo estudentizado. Um teste Anova pode dizer que os resultados encontrados são significativos no geral, mas não exatamente onde estão as diferenças. Depois de executar um teste Anova e encontrar resultados significativos, é possível executar o HSD de Tukey para descobrir que médias de grupos específicos, e comparados entre si, são diferentes. Ver: Stephanie Glen. "Tukey Test/Tukey Procedure/Honest Significant Difference" From StatisticsHowTo.com: Elementary Statistics for the rest of us!https:// www.statisticshowto.com/tukey-test-honest-significant-difference/acesso:26/01/2021.

Confluência. Rio de Janeiro: Liceu Literário Português, n. 62, p. 81-121, jan.-jun. 2022 
O procedimento estatístico empregado, o teste qui-quadrado, está habilitado para medir variáveis qualitativas, com duas ou mais categorias, além do grau de discrepância entre um conjunto de frequências esperadas e o modo como essas frequências estão associadas às duas variáveis qualitativas. O teste qui-quadrado também permite avaliar se existe ou não associação entre as variáveis qualitativas. Nesse teste, o procedimento usado para avaliar a rejeição ou não da hipótese inicial de que existe associação indica se o p-valor é maior ou menor que o nível de significância escolhido, ou seja, 0,05.

Tendo fornecido os procedimentos metodológicos e estatísticos aplicados aos testes de atitudes e de crenças, apresentamos, na sequência, os resultados, dando preferência, inicialmente, ao de atitudes, para depois tratar do de crenças, em virtude não apenas de seguir a ordem de aplicação dos testes, mas também de discutir em primeiro lugar a percepção mais indireta da variável, deixando para o segundo lugar a discussão da percepção mais direta e consciente, própria do teste de crenças.

\section{Analisando os resultados do teste de atitudes}

A tabela 1 mostra os resultados gerais do teste fornecidos pelo Anova das seis perguntas que correlaciona as respostas dos avaliadores e as dos grupos de escolaridade.

Tabela 1. Resultados do teste anova referentes às perguntas do teste de atitudes

\begin{tabular}{lllllll}
\hline Inteligente & Entre os grupos & 33,746 & 1 & 33,746 & 12,975 & 0,000 \\
& Nos grupos & 265,292 & 102 & 2,601 & & \\
& Total & 299,038 & 103 & & & \\
\hline Honesto & Entre os grupos & 8,174 & 1 & 8,174 & 1,985 & 0,162 \\
& Nos grupos & 420,047 & 102 & 4,118 & & \\
& Total & 428,221 & 103 & & & \\
\hline
\end{tabular}

continua 


\begin{tabular}{lllllll}
\hline Competente & Entre os grupos & 20,586 & 1 & 20,586 & 7,127 & 0,009 \\
& Nos grupos & 294,635 & 102 & 2,889 & & \\
& Total & 315,221 & 103 & & & \\
\hline Simpático & Entre os grupos & 60,503 & 1 & 60,503 & 18,449 & 0,000 \\
& Nos grupos & 331,225 & 101 & 3,279 & & \\
& Total & 391,728 & 102 & & & \\
\hline Rico & Entre os grupos & 9,146 & 1 & 9,146 & 3,981 & 0,049 \\
& Nos grupos & 232,058 & 101 & 2,298 & & \\
& Total & 241,204 & 102 & & & \\
\hline Boa pessoa & Entre os grupos & 60,642 & 1 & 60,642 & 15,373 & 0,000 \\
& Nos grupos & 402,349 & 102 & 3,945 & & \\
& Total & 462,990 & 103 & & & \\
\hline Escolaridade & Entre os grupos & 0,191 & 1 & 0,191 & 0,276 & 0,601 \\
& Nos grupos & 70,569 & 102 & 0,692 & & \\
& Total & 70,760 & 103 & & & \\
\hline Sexo & Entre os grupos & 0,000 & 1 & 0,000 & 0,0010 & 0,970 \\
& Nos grupos & 25,528 & 102 & 0,250 & & \\
& Total & 25,529 & 103 & & & \\
\hline
\end{tabular}

Fonte: SILVA, 2019, p. 143.

Os resultados da tabela 1 revelam que, na avaliação das qualificações "inteligente", "simpático", "boa pessoa" e "rico", o valor de p é menor que 0,05 , evidenciando que as médias dos grupos são diferentes. Já na avaliação das qualificações "honesto" e "competente", o valor de p é maior que 0,05, apontando para a ausência de uma diferença significativa entre os grupos na avaliação dos pronomes de referência ao interlocutor. Quanto à escolaridade e ao sexo, os valores de p indicam que esses fatores não exercem influência na escolha das perguntas pelos seis grupos analisados.

Numa análise mais detalhada, apresentam-se os resultados de cada uma das perguntas avaliadas nos Gráficos de 1 a 6 com a indicação das médias das notas atribuídas a cada atributo testado. Inicia-se a discussão dos dados com a análise do Gráfico 1. 


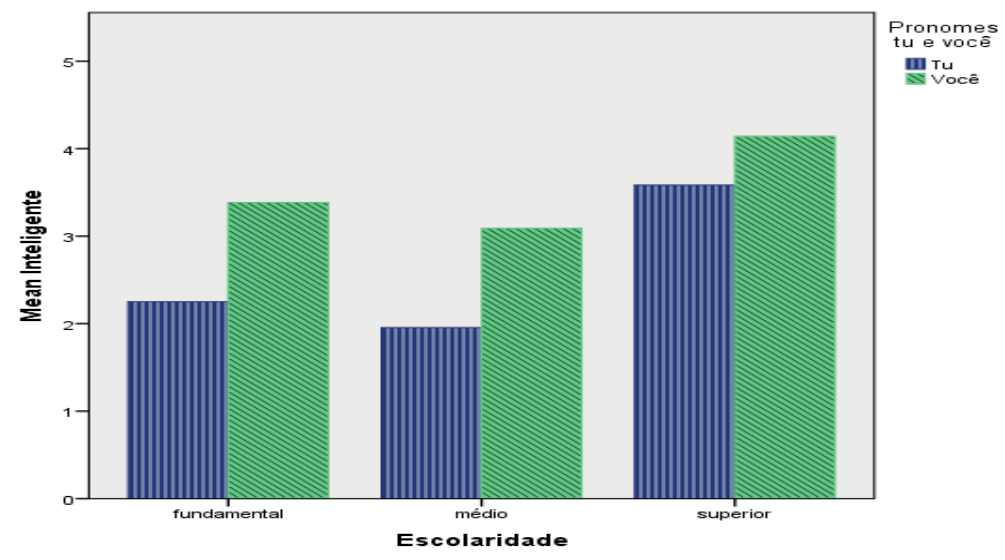

Gráfico 1. Média das notas atribuídas para "inteligente"

Fonte: SILVA, 2019, p. 144.

Tomando-se por parâmetro o atributo "inteligente", os valores mais baixos foram consignados pelos participantes de todos os níveis de escolaridade para o falante que usa $t u$, ressaltando-se que as notas mais baixas foram atribuídas pelos participantes com ensino médio e fundamental. Já para o falante usando você, os valores mais elevados foram atribuídos por avaliadores com ensino superior. Dito isso, procede-se à análise dos Gráfico 2.

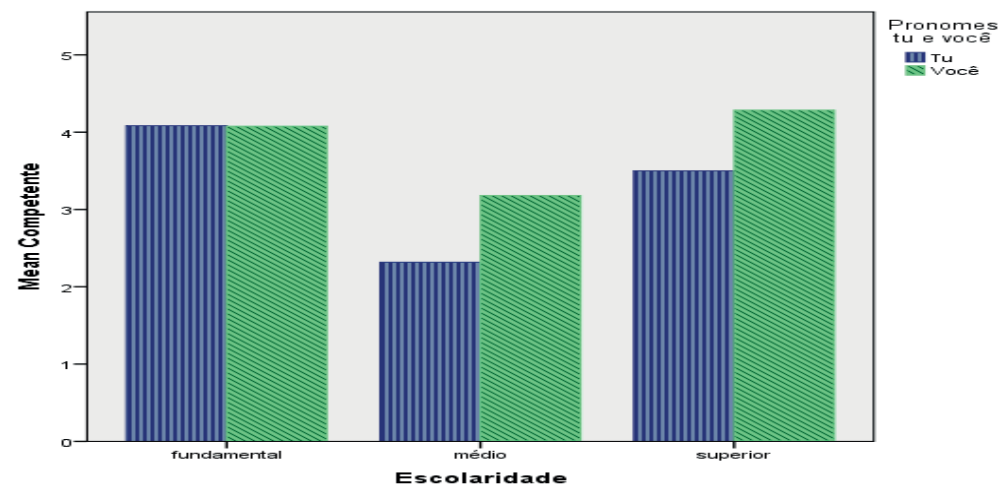

Gráfico 2. Média das notas atribuídas a "competente"

Fonte: SILVA, 2019, p. 145.

Confluência. Rio de Janeiro: Liceu Literário Português, n. 62, p. 81-121, jan.-jun. 2022 
A avaliação dos resultados para a qualificação "competente" mostra que os valores mais baixos foram atribuídos ao falante usando tu pelos participantes com grau médio de escolaridade e o índices mais elevados, ao falante usando você pelos avaliadores com ensino superior. Os avaliadores com grau fundamental de escolaridade mostram-se indiferentes às duas variantes pronominais.

Os dados de $\mathrm{p}$ dos testes Tukey e Bonferroni apontam para diferenças estatisticamente significativas para as avaliações do uso de tu e você nos grupos com ensino fundamental e médio, apresentando o valor de $\mathrm{p}$ igual a 0,05 . Assim, o fato de $\mathrm{p}$ ser menor que 0,05 sinaliza diferenças na avaliação das respostas, como aponta o valor da significância desse adjetivo analisado: 0.000. Passa-se, agora, à análise dos dados do Gráfico 3.

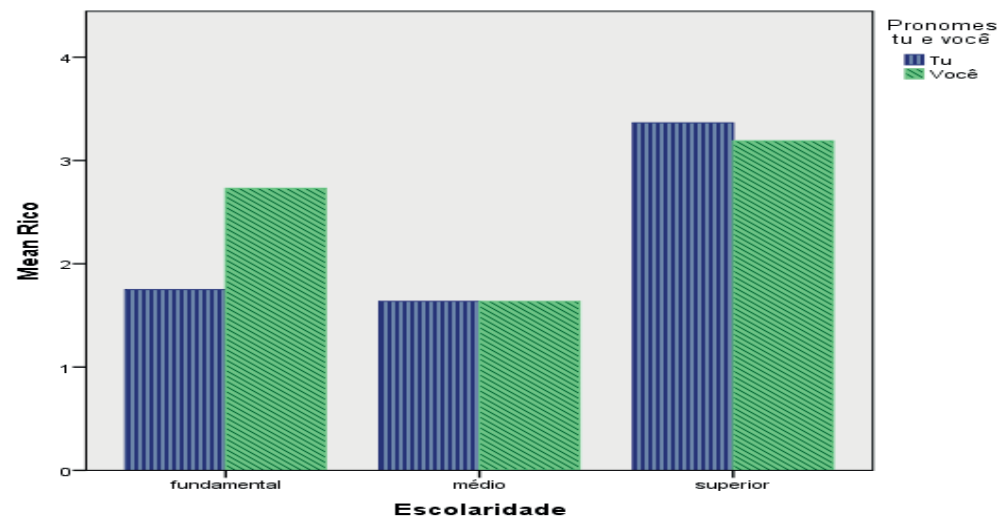

Gráfico 3. Média das notas atribuídas a "rico"

Fonte: SILVA, 2019, p. 146.

O exame das respostas envolvendo a qualificação "rico" mostra que as notas mais baixas foram atribuídas pelos participantes com ensino fundamental e médio e as mais elevadas, pelos participantes com ensino superior. Ao falante ouvido na gravação, que emprega o pronome $t u$, são os participantes com grau superior de escolaridade que atribuem as notas 
mais elevadas; diferentemente, nesse caso, de você, cujo uso é avaliado com a atribuição de valores mais elevados que o de $t u$ pelos participantes com ensino fundamental. Esses resultados apontam para a existência de diferenças significativas entre os grupos e dentro dos grupos, na avaliação do uso de tue você em relação a essa qualificação. Observe-se, agora, se esse comportamento se aplica igualmente ou não à qualificação "honesto", conforme mostram os dados do Gráfico 4.

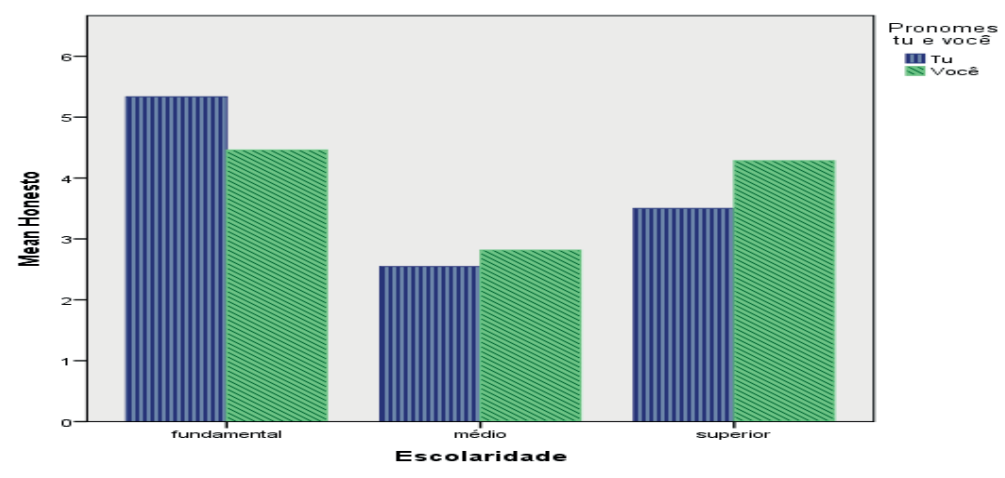

Gráfico 4. Média das notas atribuídas para "honesto"

Fonte: SILVA, 2019, p. 146.

A análise das médias dos avaliadores mostra que, em relação à percepção da honestidade, as notas mais baixas ao falante ouvido usando tu são atribuídas pelos participantes com graus mais elevados de escolaridade, ou seja, de ensino médio e superior. Os participantes com ensino fundamental se mostram indiferentes ao julgamento de do uso de $t u$ e você. Considerem-se, agora, os dados do Gráfico 5 que exibe as médias atribuídas às variantes em relação ao atributo "simpático". 


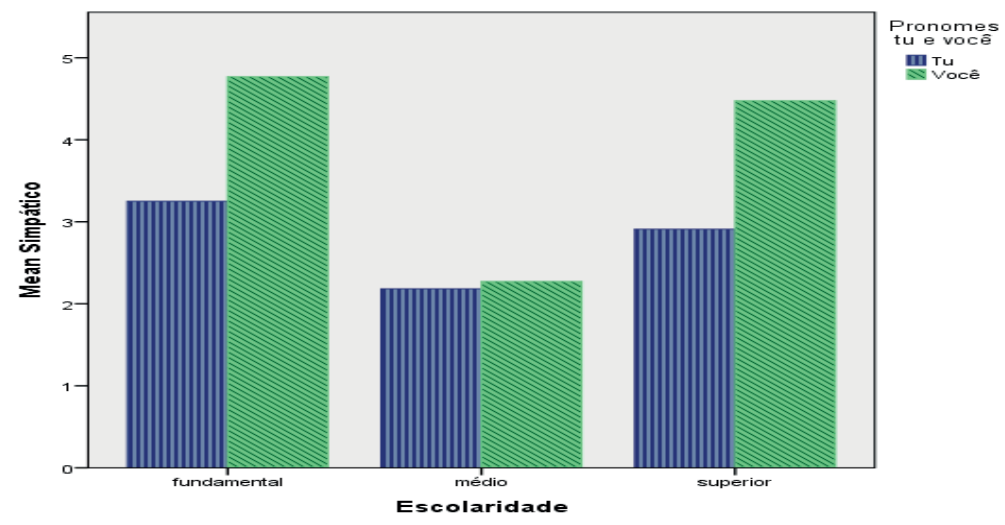

Gráfico 5. Média das notas atribuídas para "simpático"

Fonte: SILVA, 2019, p. 147.

Na avaliação do grau de simpatia, entrevê-se uma divergência entre os três grupos sociais com base nas médias de uso de $t u$ e você, pelo menos em comparação aos resultados obtidos com base em outros atributos: as médias mais elevadas são conferidas ao falante usando você pelos avaliadores com nível fundamental e superior, justamente os dois extremos da escala. As notas mais baixas são conferidas ao uso do pronome $t u$ pelos julgadores de todos os níveis de escolaridade, mas os que têm ensino médio não discriminam os falantes com base no uso de $t u$ e você. Observem-se os resultados do Gráfico 6 , relativos à qualificação "boa pessoa". 


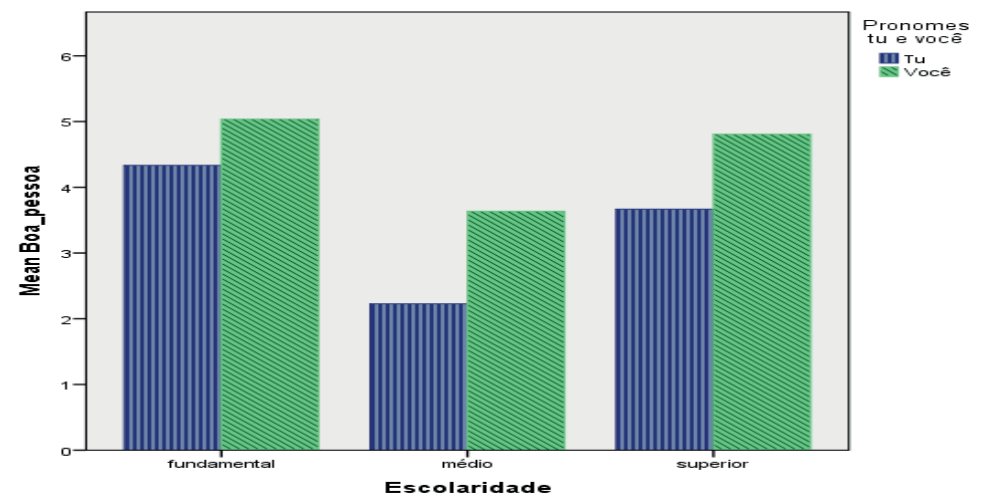

Gráfico 6. Média das notas atribuídas para "boa pessoa"

Fonte: SILVA, 2019, p. 148.

A análise dos dados relativos ao parâmetro "boa pessoa" indica que os avaliadores dos três grupos de escolaridade atribuem as notas mais elevadas ao falante usando você e as mais baixas, ao falante usando $t u$. As médias das variantes apresentam divergências estatísticas entre os três grupos, sendo que, no interior dos grupos, as médias apresentam valores significativos para todos os indivíduos analisados com p igual a 0.000 .

Deduz-se que, de modo geral, os resultados mostram que os participantes com grau superior conferem valores mais elevados a você do que a $t u$ em todas as qualificações que envolvem a dimensão do poder, ou seja, "inteligente", "competente" e "rico", e os participantes com nível médio e fundamental consignam valores mais baixos ao uso ouvido dessa variante.

Por outro lado, os resultados do exame das qualificações que envolvem a dimensão de solidariedade, ou seja, "honesto", "simpático e "boa pessoa", mostram valores mais elevados atribuídos ao uso de tu e você pelo grupo de avaliadores com nível fundamental. Na avaliação das qualificações "simpático" e "boa pessoa", consignam-se os valores mais baixos ao uso do pronome $t u$ nos três grupos, e valores mais elevados, ao uso de você. 
Esses resultados de avaliação subjetiva dos informantes dos três agrupamentos por escolaridade, que apontam para a atribuição majoritária de grau mais elevado de prestígio a você, vão ao encontro dos resultados obtidos do registro falado ${ }^{5}$, como mostram os dados da tabela 2.

Tabela 2. O uso das variantes $t u$ e você em função de escolaridade

\begin{tabular}{lllllll}
\hline Escolaridade & $\mathrm{Tu}$ & \multicolumn{5}{l}{ Você } \\
\cline { 2 - 7 } & Freq & $\%$ & $\mathrm{PR}$ & Freq & $\%$ & $\mathrm{PR}$ \\
\cline { 2 - 7 } $\begin{array}{l}\text { Ensino } \\
\text { fundamental }\end{array}$ & $12 / 44$ & 30.0 & $\mathbf{0 . 5 3}$ & $28 / 115$ & 70.0 & 0.47 \\
Ensino médio & $19 / 44$ & 34.5 & $\mathbf{0 . 5 8}$ & $36 / 115$ & 65.5 & 0.42 \\
Ensino superior & $13 / 44$ & 20.3 & 0.40 & $51 / 115$ & 79.7 & $\mathbf{0 . 6 0}$ \\
\hline Input do grupo & 0.27 & & & 0.73 & & \\
\hline Significância & 0.203 & & & & & \\
\hline
\end{tabular}

Fonte: SILVA, 2019, p. 118.

Os dados da tabela 2 permitem constatar que a forma pronominal você é a preferida na comunidade rio-branquense por falantes de todos os níveis de escolaridade, quando se olha apenas para os resultados de frequência, mas ver os resultados da perspectiva do peso relativo mostra uma situação diferente: verifica-se haver, nesse âmbito, uma distribuição complementar entre os três grupos sociais com base no seguinte comportamento: o registro falado dos informantes com ensino fundamental e médio favorece o uso de $t u$ com PR de 0.53 e 0.58 , respectivamente, enquanto o registro falado dos informantes com ensino superior favorece o uso de você com PR de 0.60 .

5 É conveniente esclarecer que, embora sejam todos moradores nascidos em Rio Branco no Acre, não são os mesmos os informantes que forneceram os dados do registro da fala e os informantes que forneceram os da avaliação subjetiva, nem houve simultaneidade no levantamento.

Confluência. Rio de Janeiro: Liceu Literário Português, n. 62, p. 81-121, jan.-jun. 2022 
Para interpretar esses dados, invoca-se o processo de aquisição de uma variedade padrão proposta por Labov (1974), que identifica seis estágios: a gramática básica, o vernáculo, a percepção social, a variação estilística, o standard consistente e, por fim, a totalidade da amplitude. Esse processo parece aplicar-se, conforme se verá, ao comportamento dos participantes, que atuaram como avaliadores do grau de prestígio ou estigma das variantes examinadas.

Os participantes com ensino fundamental especialmente, mas também, em grande parte, os com ensino médio, estariam na fase da percepção social, quando passam a ter contato com falantes de um contexto diferente do compartilhado com os pais, instalando-se, portanto, em sua consciência linguística, o significado social da variedade de seus pares para a qual passam a voltar-se no uso. De acordo com Labov (1974), ao apresentarem atitudes linguísticas semelhantes às dos adultos, os adolescentes em estágio inicial de escolaridade passam a identificar o valor social de formas em variação. A crescente conscientização social associada aos usos linguísticos produz uma mudança em sua fala na direção da variedade de prestígio.

Já os participantes com ensino superior estariam no nível de standard consistente, fase em que os falantes têm consciência de que não basta apenas usar formas prestigiosas esporadicamente, mas é necessário também ser capaz de manter consistentemente o uso delas, conforme requerem as circunstâncias de interação social, ou seja, as mais prestigiosas em situações formais e as menos prestigiosas em situações informais. É possível, portanto, atribuir a esse grau de consciência social o apego do grupo de participantes com o grau mais elevado de escolaridade aos valores de prestígio da variante você.

Os participantes com ensino superior são os que atribuem com maior frequência valores de prestígio à variante você, seguidos dos que dispõem de ensino fundamental. Vale notar que, no registro falado, o comportamento dos informantes com nível médio se aproxima do comportamento dos que têm nível fundamental. Em todos os parâmetros de análise do teste de atitudes, a aproximação é maior entre informantes com ensino fundamental e informantes 
com ensino superior. Como, todavia, a percepção do valor social de você está mais vinculada à dimensão do poder, é possível deduzir que é essa a variante com o maior grau de prestígio e a variante $t u$, talvez não exatamente estigmatizada, mas neutra, estaria mais correlacionada às dimensões de solidariedade. Esse valor não deixa, portanto, de estar simbolicamente ligado ao fato de que é nas relações socialmente simétricas de papel e nos discursos mais familiares que tu prevalece quando olhamos para a outra dimensão da variável, o registro falado em si.

Para examinar essa relação, invocou-se um trabalho pioneiro de Head (1976) sobre as formas de tratamento $t u$, você e $o(a)$ senhor(a), que assume, como principal variável social, as relações de papel entre interlocutores de diferentes domínios, como família, escola e trabalho. Os resultados demonstram a predominância de um sistema binário simples: o(a) senhor(a) como forma deferencial; tu ou você como forma não deferencial ou íntima, com dois padrões, especialmente frequentes: o recíproco e o não recíproco.

Mais recentemente, o trabalho de Nunes de Sousa e Coelho (2015) inclui cartas entre noivos, com temática amorosa, e entre amigos, com temática de natureza ora profissional, ora mais pessoal. As relações interpessoais mais íntimas ativam nessas cartas o uso de $t u$. Por outro lado, Scherre, Yacovenco e Scardua (2018) estudaram as formas de tratamento nas cartas pessoais de Oswald Cruz Guimarães, escritas no século XX. Nessas cartas, as pesquisadoras procuraram detectar que tipos de relações se estabelecem entre os interlocutores, se simétricas ou assimétricas. Os resultados a que chegaram as autoras mostram que as formas pronominais $t u$ e você são usadas apenas no contexto familiar mais íntimo. Em função desse fato, elas passam, então, a analisar o tópico discursivo, entendido como o conteúdo sobre o qual se fala durante o evento comunicativo. Detectados os tópicos amor, pedido, notícia e crítica, os resultados demonstram que os dois primeiros favorecem o uso do pronome $t u$ (0.763), ao passo que os dois últimos o desfavorecem (0.425). Com base nesses dados, as autoras afirmam que é $t u$ que representa maior intimidade, uma vez que emerge com maior frequência principalmente nos 
tópicos de maior grau de envolvimento emocional. O pronome você, por outro lado, expressa distanciamento, justamente por ser empregado nos tópicos que implicam menor grau de envolvimento emocional.

Essas pesquisas serviram de âncora para a decisão metodológica que se tomou de investigar as relações interpessoais presentes no discurso da comunidade rio-branquense, enfocando, na análise, as relações de papel ${ }^{6}$ entre os interlocutores de diferentes domínios discursivos, como o familiar, o escolar e o profissional (FISHMAN, 1971).

Centrou-se o olhar nos enunciados que contêm discursos reportados, justamente por ser nesse gênero que se torna possível vislumbrar o exercício de diferentes relações de papel entre os interlocutores envolvidos. A amostra de discurso reportado contém três domínios discursivos, identificados como familiar, escolar e profissional, cuja análise permitiu identificar diferentes relações interpessoais. O domínio familiar, em que os participantes envolvidos assumem o mesmo papel social em relações simétricas e informais, favorece o uso de $t u$, como nos exemplos (9) e (10), que se afiguram como casos de discursos reportados entre irmãos e entre cônjuges, respectivamente.

(9) ... aí minhas irmãs disseram: vai que tu consegue. (Corpus GELAC - Entr. 64)

(10) ....aí meu pai falo: É quem sabe é tu. (Corpus GELAC - Entr. 64)

Em discursos reportados envolvendo amigos, a probabilidade de uso é igual para as formas $t u$ e você. Em relações simétricas, com certo grau de distanciamento entre os participantes envolvidos, dá-se preferência ao uso de você com exclusividade, como no caso dos discursos reportados entre vizinho e cunhado. O exemplo (11) ilustra essas escolhas pronominais em discurso reportado envolvendo vizinhos.

6 Entende-se, por papel, o modo de o indivíduo desempenhar de fato as exigências de determinada posição (DAVIS, 1961 apud Camacho, 2015).

Confluência. Rio de Janeiro: Liceu Literário Português, n. 62, p. 81-121, jan.-jun. 2022 
(11) Eli disse não vizinha, se você subesse o meu aperreio qui eu tô você não perguntava si eu durmu, si eu não durmu você não deixa de durmi qui você não tá no meu lugá si você tivesse no meu lugá num perguntava isso não... (Corpus GELAC - Entr. 92)

Nos discursos reportados entre pais e filhos, prevalece uma troca mútua de tu e você configurando, igualmente, uma relação de intimidade, como mostram os exemplos (12) e (13).

(12) Aí minha mãe disse assim: si você não pegá você vai apanhar u dobro, vai apanhá por você e por eli. (Corpus GELAC - Entr. 63)

(13) Aconselha, ...semana passada ele falou para mim “ se tu fô namorá tu presta atenção. (Corpus GELAC - Entr. 21)

No domínio profissional, por seu lado, os resultados da análise de discursos reportados envolvendo papéis sociais de médico e paciente apontam para índices iguais de $t u$ e você. Já quando os papeis envolvidos são os de patrão e empregado, a relação nitidamente assimétrica ativa um padrão não recíproco, segundo o qual o interlocutor em posição inferior emprega a forma de tratamento $o(a)$ senhor (a) e recebe em troca ora $t u$ ora você. O exemplo (14) mostra um fragmento discursivo de discurso reportado favorecendo essas escolhas.

(14) Eu digu tudu bem. E com o senhor? Tudu bem. O quê qui tu anda fazendu? Aí eu olhei pra cara deli e disse: O sinhô sabe o qui eu andu fazendu...

Ela dissi: Zé mas tu só fica olhandu. (Corpus GELAC - Entr. ^^)

Se, por um lado, é verdade que a amostra em que se baseou esta análise é mais qualitativa que quantitativa, por não ser possível contar com um conjunto massivo de dados, não é menos verdade, por outro, que a análise forneceu evidência relevante de relações de tratamento deferencial, encontradas em situações formais, e relações de tratamento não deferencial, 
presentes em situações informais. Os resultados da relação entre tratamento ao interlocutor e situações de interação apontam para o uso do pronome $t u$ em contextos íntimos e informais e o do pronome você em contextos formais e não familiares, reservando-se ainda para $o(a)$ senhor (a) o tratamento mais deferencial com base em relações sociais assimétricas de poder.

\section{Confirmando os resultados por escolaridade: $o$ teste de crenças}

A seção precedente mostrou haver resultados convergentes entre a análise das reações subjetivas, mediante aplicação do teste de atitudes, e a dimensão do registro falado real, mediante o cruzamento entre uso das duas variantes e a variável escolaridade. Em função dessa convergência, procedeuse à análise do teste de crenças, cujos resultados, obtidos pelo Anova, estão dispostos na tabela 3 .

Tabela 3. Resultados do teste de crenças em relação ao uso das variantes tu e você

\begin{tabular}{lllllll}
\hline & & $\begin{array}{l}\text { Soma dos } \\
\text { quadrados }\end{array}$ & $\begin{array}{l}\text { Grau de } \\
\text { liberdade }\end{array}$ & $\begin{array}{l}\text { Média dos } \\
\text { quadrados }\end{array}$ & F & P \\
\hline Você acha que esta & Entre grupos & 0,215 & 1 & 0,215 & 0,171 & 0,682 \\
pessoa está em que & Nos grupos & 35,152 & 28 & 1,255 & & \\
faixa etária? & Total & 35,367 & 29 & & & \\
\hline Você acha que esta & Entre grupos & 0,288 & 1 & 0,288 & 0,755 & 0,392 \\
pessoa estudou... & Nos grupos & 10,679 & 28 & 0,381 & & \\
& Total & 10,967 & 29 & & & \\
\hline Você acha que esta & Entre grupos & 0,086 & 1 & 0,086 & 0,292 & 0,593 \\
pessoa pertence à... & Nos grupos & 8,214 & 28 & 0,293 & & \\
& Total & 8,300 & 29 & & & \\
\hline Essa pessoa fala & Entre Grupos & 0,815 & 1 & 0,815 & 3,430 & 0,075 \\
bem? & Nos grupos & 6,652 & 28 & 0,238 & & \\
& Total & 7,467 & 29 & & & \\
\hline
\end{tabular}




\begin{tabular}{lllllll}
\hline Essa forma de uso & Entre Grupos & 0,288 & 1 & 0,288 & 1,124 & 0,298 \\
é adequada? & Nos Grupos & 7,179 & 28 & 0,256 & & \\
& Total & 7,467 & 29 & & & \\
\hline Essa pessoa mora & Entre Grupos & 0,010 & 1 & 0,010 & 0,050 & 0,825 \\
no perímetro & Nos Grupos & 5,357 & 28 & 0,191 & & \\
urbano? & Total & 5,367 & 29 & & & \\
\hline Escolaridade & Entre grupos & 0,536 & 1 & 0,536 & 0,771 & 0,387 \\
& Nos Grupos & 19,464 & 28 & 0,695 & & \\
& Total & 20,000 & 29 & & & \\
\hline Sexo & Entre Grupos & 0,315 & 1 & 0,315 & 1,233 & 0,276 \\
& Nos Grupos & 7,152 & 28 & 0,255 & & \\
& Total & 7,467 & 29 & & & \\
\hline
\end{tabular}

Fonte: SILVA, 2019, p. 150.

Esse teste envolveu a apresentação de seis variáveis quantitativas ou nominais, três com opções de alternativas para livre escolha do avaliador e três perguntas com duas opções, verdadeira ou falsa. Para cada afirmativa, procurou-se verificar a diferença entre as percepções dos usos dos pronomes tu e você, analisadas mediante a proporção relativa das respostas dos três grupos de participantes: respondentes com ensino fundamental, médio e superior.

Os resultados revelam que, majoritariamente, o valor de $\mathrm{p}$ é menor que 0,05 , o que fornece evidências de compatibilidade das médias dos grupos. Nessa análise, os valores de $\mathrm{p}$ indicam que os grupos por escolaridade a que pertence o participante avaliador não exercem influência na escolha das perguntas dos seis grupos analisados.

A análise dos valores de $\mathrm{f}$ mostra que, mesmo não havendo, nos três grupos analisados, um grau relevante de significância para a avaliação das perguntas, encontramos níveis diferentes de média entre as respostas, mostrando que há uma diferença entre a avaliação de $t u$ e você entre os grupos e mesmo no interior dos grupos: observe-se que, em alguns grupos, o valor 
de f é extremamente elevado, como quando aplicado à pergunta "Essa pessoa fala bem?". Para verificar essas diferenças, procedeu-se a uma análise mais refinada, mais específica, limitando-se, porém a três variáveis cruciais para a discussão realizada na seção anterior, que diz respeito à relação entre as duas variantes para referência ao interlocutor e a escolaridade dos respondentes.

Comecemos, então, pelos dados da tabela 4 , relativos à resposta à pergunta Você acha que esta pessoa estudou até que série?

Tabela 4. Respostas à pergunta "Você acha que esta pessoa estudou até que série?"

\begin{tabular}{llllllll}
\hline & \multicolumn{2}{l}{ Fundamental } & \multicolumn{2}{l}{ Médio } & \multicolumn{2}{c}{ Superior } & Total \\
& Tu & Você & Tu & Você & Tu & Você & \\
\hline Fundamental & 0 & 2 & 3 & 0 & 0 & 0 & 5 \\
Médio & 4 & 2 & 2 & 4 & 3 & 4 & 19 \\
Superior & 1 & 1 & 1 & 0 & 0 & 3 & 6 \\
\hline Total & 5 & 5 & 6 & 4 & 3 & 7 & 30 \\
\hline Média do grupo & 2,00 & & 1,80 & & 2,30 & & \\
Significância & 0,191 & & & & & & \\
\hline
\end{tabular}

Fonte: SILVA, 2019, p. 153.

A análise da variável escolaridade indica haver convergência na atribuição das respostas dos julgadores com ensino fundamental ao uso indiferente de $t u$ e de você, o que diverge fundamentalmente dos julgadores com ensino médio, que atribuem o uso de $t u$ ao menor grau de escolaridade: com efeito, atribuem-se 3 de 6 avaliações de tu a falantes do ensino fundamental. Já a avaliação dos ouvintes com ensino superior mostra que eles conferem o uso de você aos falantes com o nível mais elevado de escolaridade.

Reporte-se, agora aos dados da tabela 5, relativos às respostas estimuladas pela pergunta Você acha que essa pessoa pertence à que classe social? 
Tabela 5. Respostas à pergunta "Você acha que esta pessoa pertence à que classe social?"

\begin{tabular}{llllllll}
\hline \multirow{2}{*}{ Classe social } & \multicolumn{2}{l}{ Fundamental } & \multicolumn{2}{l}{ Médio } & \multicolumn{2}{c}{ Superior } & Total \\
& Tu & Você & Tu & Você & Tu & Você & \\
\hline Classe baixa & 0 & 2 & 3 & 1 & 2 & 2 & 10 \\
Classe média & 5 & 2 & 3 & 3 & 1 & 5 & 19 \\
Classe alta & 0 & 1 & 0 & 0 & 0 & 0 & 1 \\
\hline Total & 5 & 5 & 6 & 4 & 3 & 7 & 30 \\
\hline Média do grupo & 1,90 & & 1,60 & & 1,60 & & \\
Significância & 0,363 & & & & & & \\
\hline
\end{tabular}

Fonte: SILVA, 2019, p. 153.

Os resultados mostram que os avaliadores com ensino fundamental não veem diferenças significativas de uso entre os pronomes de referência à segunda pessoa. Já os julgadores com ensino médio atribuem o uso de você a falantes de classe média: 3 de 4 casos a falantes de classe média e 1, a falantes de classe baixa. Resultado similar ocorre no julgamento dos informantes com nível superior, que atribuem 5 de 7 casos de você ao uso de falantes de classe média e 2, a falantes de classe baixa.

Procede-se, agora, à análise dos dados dispostos na tabela 6, em que se analisam as respostas estimuladas para a pergunta Essa pessoa fala bem?

Tabela 6. Respostas à pergunta "Essa pessoa fala bem?"

\begin{tabular}{llllllll}
\hline & \multicolumn{2}{l}{ Fundamental } & \multicolumn{2}{l}{ Médio } & \multicolumn{2}{l}{ Superior } \\
& Tu & Você & Tu & Você & Tu & Você & Total \\
\hline Sim & 3 & 1 & 1 & 3 & 1 & 7 & 16 \\
Não & 2 & 4 & 5 & 1 & 2 & 0 & 14 \\
\hline Total & 5 & 5 & 6 & 4 & 3 & 7 & 30 \\
\hline Média do grupo & 1,60 & & 1,60 & & 1,20 & & \\
Significância & 0,125 & & & & & & \\
\hline
\end{tabular}

Fonte: SILVA, 2019, p. 154.

Confluência. Rio de Janeiro: Liceu Literário Português, n. 62, p. 81-121, jan.-jun. 2022 
Os valores quantitativos mostram que os avaliadores com ensino fundamental atribuem valores iguais ao uso de $t u$ e voce, diferentemente dos avaliadores com ensino médio e superior, que preferem atribuir "falar bem" ao uso de você e "não falar bem", ao uso de tu. Os valores médios de uso de $t u$ e de você confirmam a hipótese de que existe uma identidade entre os julgamentos de uso das formas pronominais, em função dos valores muito próximos para os pronomes $t u$ e você.

Considerem-se agora os resultados da tabela 7, referentes à avaliação da pergunta Essa forma de uso é adequada?

Tabela 7. Respostas à pergunta Essa forma de uso é adequada?

\begin{tabular}{llllllll}
\hline & \multicolumn{2}{c}{ Fundamental } & \multicolumn{2}{c}{ Médio } & \multicolumn{2}{c}{ Superior } & Total \\
& $\mathrm{Tu}$ & Você & $\mathrm{Tu}$ & Você & $\mathrm{Tu}$ & Você & \\
\hline Sim & 3 & 2 & 1 & 2 & 2 & 6 & 16 \\
Não & 2 & 3 & 5 & 2 & 1 & 1 & 14 \\
\hline Total & 5 & 5 & 6 & 4 & 3 & 7 & 30 \\
\hline Média do grupo & 1,50 & & 1,70 & & 1,20 & & \\
Significância & 0,081 & & & & & & \\
\hline
\end{tabular}

Fonte: SILVA, 2019, p. 155.

Verifica-se haver nos julgamentos dos participantes com ensino fundamental uma distribuição equilibrada em relação às duas formas pronominais. Os participantes com ensino superior preferem julgar mais adequado o uso da forma você, contrapondo-se aos julgamentos dos participantes com ensino médio, que avaliam como mais adequados os usos de tu. Como é de se esperar, os participantes com ensino médio ora tendem a agrupar-se com os que têm ensino fundamental ora, com os que têm ensino superior.

Para testar com mais acuidade o grau de consciência dos falantes, aplicaram-se testes de insegurança linguística, como proposto por Labov (2008 [1972]). Nesse texto, Labov (2008 [1972], p. 251) defende que toda 
comunidade conta com falantes mais conscientes do que outros sobre as formas de uso da língua no contexto social, mostrando um comportamento motivado por padrões externos de natureza normativa. Por isso, esses falantes exibem um grau mais elevado de alternância que os que não são capazes de identificarem claramente esses padrões. Para os testes, incluíram-se duas perguntas inquirindo o participante sobre qual dentre as duas formas é a correta e, em seguida, qual delas ele mesmo usa de fato. De acordo com Labov (2008 [1972]), o número total de itens em que as duas respostas diferem constitui um quociente seguro de insegurança linguística. A tabela 8 exibe essas medidas gerais de insegurança linguística.

Tabela 8. Distribuição dos valores gerais dos testes de Insegurança linguística

\begin{tabular}{lllll}
\hline & & \multicolumn{3}{l}{ Escolaridade } \\
\cline { 3 - 5 } & & $\mathrm{M}$ & $\mathrm{S}$ & \\
\hline Qual é a forma mais & Você qué(r) um sorvete? & 8 & 8 & 10 \\
adequada para você? & Tu qué(r) um sorvete? & 2 & 2 & 00 \\
\hline Qual a forma que & Você qué(r) um sorvete? & 5 & 5 & 09 \\
você usa mais? & Tu qué(r) um sorvete? & 5 & 5 & 01 \\
\hline
\end{tabular}

Fonte: SILVA, 2019, p. 156.

Aplicou-se inicialmente o teste Anova, para testar as hipóteses iniciais. A pergunta "Qual das duas perguntas é mais adequada pra você??" produziu um valor da significância de 0.262 e a segunda, "Qual das duas perguntas você usa mais?" produziu um valor de significância de 0.150 . Como os valores de p para as duas questões são maiores que 0.05 , é possível concluir que se conta com um grau razoavelmente homogêneo de variância.

Os valores da tabela 8 permitem constatar a existência de uma similaridade nos resultados qualitativos na avaliação dos participantes com ensino médio e com ensino fundamental. O julgamento da pergunta 1 forneceu os mesmos resultados para as duas opções: 8 de 10 informantes 
julgam adequada a opção com você e apenas 2 participantes consideram adequada a opção com $t u$.

No julgamento da pergunta 2, as respostas dos avaliadores com ensino médio e fundamental apresentam resultados idênticos para o uso de você e tu: 5 de 10 informantes julgam usar você com mais frequência e 5, a variante $t u$. De qualquer modo, essa discrepância entre o conceito de adequação e o uso real mostra certo grau de insegurança linguística dos participantes com ensino fundamental e médio. Essa insegurança, própria dos falantes em fase de aquisição, tem certamente algo a ver com o fato de que é você a forma mais prestigiosa especialmente em virtude de ser empregada em situações formais, restando a $t u$ certo grau de prestígio encoberto, na medida em que seu uso predomina nas relações mais familiares.

Os participantes com ensino superior, por seu lado, julgam, na resposta à questão 1 , que o uso do você é mais adequado que o de $t u$. Na resposta $a$ que forma usam mais apenas 1 de 10 participantes marca a forma $t u$. Os valores de frequência mostram, portanto, uma convergência entre adequação e crença no que se usa de fato no que concerne ao julgamento dos participantes com ensino superior.

Os resultados deixam claro que, na consciência dos avaliadores com ensino superior, o uso do pronome você está marcado por relações de poder, o que é perfeitamente compatível com outros resultados do teste de atitudes em que se julga ser o pronome você próprio do uso de falantes com nível mais elevado de escolaridade e $t u$, de falantes com grau mais baixo. $\mathrm{O}$ valor simbólico dessa identificação é o de que usar você denota "falar bem", "falar adequado", diferentemente de usar $t u$. Em contrapartida, os julgamentos fornecidos pelos participantes com ensino fundamental e médio, no geral, não atribuem valores relacionados à dimensão do poder a nenhuma das formas pronominais estudadas, o que representa certo equilíbrio entre as respostas.

Resumindo-se a análise fornecida nesta seção, vê-se que, de um modo geral, os resultados dos testes de atitude e de crenças são consistentes com a atribuição de prestígio a você, especialmente pelos informantes que estão no 
topo da escala de escolaridade. O comportamento mais errático dos julgadores com ensino fundamental e médio, associado ao grau relativamente baixo de compatibilidade da relação entre adequação e uso, pode estar vinculado ao fato de que o uso de $t u$, em que pese seu baixo grau de prestígio no eixo do poder, tem a valoração positiva garantida quando o eixo envolvido é o da solidariedade. Essa diferença mostra uma correlação muito significativa entre a dimensão do uso no registro falado e a dimensão da reação subjetiva, já que, nas situações em que predominam relações interpessoais de solidariedade é o uso de $t u$ que prevalece.

Além disso, os testes de crenças serviram para mostrar também que julgadores na faixa média da escala de escolaridade tendem para convergir ora com os da faixa inferior, ora com os da faixa superior; servem para demonstrar também que, em termos de (in)segurança linguística, são os informantes com ensino superior que mostram resultados mais compatíveis para a relação entre adequação e uso, justamente o que estão mais próximos de atingir o estágio do padrão consistente nos estágios de aquisição de uma língua padrão propostos por Labov (1974)

\section{Considerações finais}

Agora, para finalizar, é tempo de fazer um balanço geral. Propôs-se responder a duas perguntas de pesquisa, que se repetem aqui por conveniência: (i) é possível atribuir à forma $t u$ um valor de prestígio encoberto, que se pode detectar em relações interpessoais de natureza informal, em oposição à forma você, a mais prestigiosa por ser exigida em situações formais? (ii) As atitudes de prestígio, que emergem da reação subjetiva, estão correlacionadas a diferenças marcadas de uso, em situações de grau maior, ou de menor, de informalidade?

O percurso da análise permite afirmar que as duas perguntas tiveram, da aplicação do teste de atitudes, uma resposta positiva em direção às seguintes conclusões: (i) os dados analisados com base na dimensão do poder apontaram 
para a existência de um valor de prestígio atribuído a você, que se origina, de modo geral, dos julgadores com grau superior de escolaridade; (ii) todavia, os dados analisados com base na dimensão de solidariedade apontaram para uma aceitação maior por $t u$ de todos os grupos de avaliadores.

As relações entre (i) e (ii) facultam, finalmente, deduzir (iii) que o exame da variável na dimensão subjetiva sinaliza compatibilidade de resultados com o exame da variável na dimensão objetiva, ainda que não sejam os mesmos informantes envolvidos nos dois tipos de levantamento. Se, por um lado, são os informantes com ensino superior, justamente os que mais se conformam com os valores normativos em razão dos anos de escolaridade, que dão maior preferência por você na dimensão do poder, por outro, esses resultados se diluem entre julgadores dos três níveis de escolaridade, quando os atributos examinados se enfeixam na dimensão da solidariedade, em que a preferência aponta para $t u$. Mais relevante ainda é que esse favorecimento está fortemente correlacionado ao fato de que é nas relações socialmente simétricas de papel e nos discursos mais familiares que $t u$ prevalece, quando se olha para a análise da variável no registro falado.

A análise dos resultados relativos ao contexto de discurso reportado permitiu constatar que o uso dos pronomes tu e você está relacionado ao modo como o falante se adapta à situação de interação, mediante um favorecimento muito maior, mas também não categórico, de $t u$ nas relações socialmente simétricas, em que o registro do discurso é também informal. Esse favorecimento é um indício da preservação de valores de distância e formalidade para o uso de você e de familiaridade e informalidade para o uso de $t u$, em confirmação à hipótese de que o uso das formas tu e você representaria distinções de formalidade ou familiaridade da situação discursiva.

O contexto de discurso reportado inclui três tipos de registros: o familiar, o escolar e o profissional. $\mathrm{O}$ uso na registro familiar aponta para evidências de que, quanto mais íntimas forem as relações entre os indivíduos, tanto maior o favorecimento do pronome $t u$, especialmente nas relações simétricas. No registro escolar, predomina a forma você, e no profissional, em 
que as relações pessoais majoritárias são assimétricas, as formas tu e você são dirigidas ao interlocutor em posição inferior, enquanto $o(a)$ senhor $(a)$ é dirigida ao indivíduo em posição superior, denotando, portanto, relações de poder e não de solidariedade (BROWN; GILMAN, 1960) entre os interlocutores. Ausentes essas relações de poder, a predominância das relações simétricas conduz à preferência pelo uso recíproco de $t u$ e você.

Pode-se lembrar, a esse propósito, que comportamento similar foi detectado por Nunes de Souza e Coelho (2015) e Scherre, Yacovenco e Scardua (2018). No que tange às relações de simetria e assimetria estabelecidas entre remetentes e destinatários, a Amostra Cruz e Sousa, cujos dados foram discutidos por Nunes de Sousa e Coelho (2015), inclui cartas entre noivos, com temática amorosa, e entre amigos, com temática de natureza ora profissional, ora pessoal. As relações interpessoais mais íntimas ativam nessas cartas o uso de $t u$, que ainda predomina na variedade de Florianópolis para esse tipo de registro. Já os resultados a que chegaram Scherre, Yacovenco e Scardua (2018) apontam para o uso de $t u$ e você apenas no contexto familiar mais íntimo, situação que levou as autoras a incluir diferenças de tópico discursivo na análise. Os resultados demonstraram que são justamente os tópicos de maior grau de intimidade que favorecem o uso de $t u$.

É possível generalizar, portanto, com base dados analisados da variedade falada em Rio Branco, comparados aos desses autores, a existência potencial de universalidade no português brasileiro, no tocante às variedades que dispõem da alternância $t u$ e você na referência determinada, do uso de $t u$ para situações de mais intimidade e familiaridade entre os interlocutores

O teste de crenças, por seu lado, mostrou certo grau de compatibilidade com o de atitudes, especialmente por ter mostrado que julgadores na faixa média da escala de escolaridade tendem ora para convergir com os da faixa de baixo, com ensino fundamental, ora com os da faixa de cima, com ensino superior. Correlacionado a esse tipo de comportamento, o teste de crenças demonstrou também que, em termos de (in)segurança linguística, são os informantes com ensino superior que mostram resultados mais compatíveis em termos da relação 
entre o que creem ser mais adequado e o que acham que usam, o que não é uma propriedade dos julgadores com ensino fundamental e médio.

Para concluir, de um ponto de vista metodológico, este trabalho reafirma a premissa teórica de que estudar uma língua implica levar em conta o Paradoxo Cumulativo, como afirma Labov (2008, p. 236), segundo o qual quanto mais se conhece de uma língua, mais é possível descobrir a respeito dela. Em que pesem todos os problemas enfrentados no desenvolvimento deste estudo, de resto, próprio da pesquisa científica, é um fato não sujeito a controvérsia que os resultados de avaliação subjetiva discutidos ampliaram o entendimento do uso das formas pronominais tu e você na variedade falada em Rio Branco e sobre o uso variável delas para a comunidade falante do português brasileiro em geral, na medida em que foi possível adicionar mais um degrau na escada que fornece, do alto, um panorama da variação pronominal no português brasileiro.

\section{Referências}

AGUILERA, V. de A. Crenças e atitudes linguísticas: quem fala a língua brasileira? In: Roncarati, Cláudia; Abraçado, Jussara. (Org.). Português brasileiro II: contato linguístico, heterogeneidade e história. Niterói: Editora Federal Fluminense, 2008.

BORTONI-RICARDO, S.M. Nós cheguemu na escola, e agora?: sociolinguística \& educação. São Paulo: Parábola, 2005.

BROWN, R.; GILMAN, A. The pronouns of power and solidarity. In: SEBEOK, T. (ed.), Style in Language. Cambridge: MIT Press, 1960, p. 253276.

CAMACHO, R. G. Da linguística formal à linguística social. São Paulo: Parábola, 2013.

CAMACHO, R. G. Formas de tratamento numa história em quadrinhos. Revista (Con) Textos Linguísticos (UFES). v.9, p.162 - 181, 2015. 
CAMACHO, R.G.; FIAMENGUI, A.H.R. Atitudes e crenças linguísticas em um cenário multilíngue. Revista da ANPOLL. v. 1, no 49, p. 91-104, Florianópolis, Jul./Set 2019.

CHAMBERS, J. K. Sociolinguistic theory. Linguistic variation and its social significance. Oxford/Cambridge: Blackwell,1996.

COELHO, I. L.; VIEIRA-PINTO, C. A. O encaixamento da mudança sintática em cartas pessoais de Santa Catarina: ordem do sujeito e objeto direto anafórico. Veredas - Revista de Estudos Linguísticos, v. 22, p. 114$133,2018$.

CONNER, M. T. et al. Relations between Implicit and Explicit Measures of Attitudes and Measures of Behavior: Evidence of Moderation by Individual Difference Variables. Personality and Social Psychology of Language, 187/188, p. 1727-1740, 2007.

CYRANKA, L. F. de M. Atitudes linguísticas de alunos de escolas públicas de Juiz de Fora - MG. 174 f. Tese (Doutorado em Estudos Linguísticos). Programa de Pós-Graduação em Letras. Instituto de Letras, Universidade Federal Fluminense, Niterói, 2007.

FIAMENGUI, A. H. R. Multilinguismo e preconceito na fronteira Porã: um estudo sobre atitudes e crenças linguísticas. Tese (Doutorado). Programa de Pós-Graduação em Estudos Linguísticos. Universidade Estadual Paulista, Instituto de Biociências, Letras e Ciências Exatas, São José do Rio Preto, 2017.

HEAD, B. F. Social factors in the use of pronouns for the addressee in Brazilian Portuguese. In: SCHMIDT-RADEFELT, J. (ed), Readings in Portuguese Linguistic. Amsterdam: North-Holland Publishing Company, 1976, p. 289348.

FISHMAN, J. A. Bilingualism in the barrio. Bloomington, Indiana: Indiana University Press, 1971. 
LABOV, W. Estágios na aquisição do inglês standard. In: FONSECA, M.S.V.; NEVES, M.F. (orgs.) Sociolingüística. Rio de Janeiro: Eldorado, 1974. p. 4986.

LABOV, W. Padrões Sociolinguísticos. São Paulo: Parábola editora, [1972] 2008.

LAMBERT, W. E. et al. Evaluation reaction to spoken language. Journal of Abnormal and social psychology, v. 60, 1960, p. 44-51.

MENDES, R. B.; OUSHIRO, L. 2012. O paulistano no mapa sociolinguístico brasileiro. Alfa, São Paulo, 56(3): 973-1001.

NUNES de SOUZA, C. M.; COELHO, I. L. Caminhos para a investigação da alternância de pronomes de segunda pessoa em Santa Catarina. LaborHistórico, v. 1, p. 49-61, 2015.

OUSHIRO, L. 2015. Identidade na pluralidade. Avaliação, percepção e produção linguística na cidade de São Paulo. 2015. 372f. Tese (Doutorado em Linguística) - Faculdade de Filosofia e Ciências Humanas, Universidade de São Paulo, São Paulo.

SANTOS, E. dos. Certo ou errado? Atitudes e crenças no ensino da língua portuguesa. Rio de Janeiro: Graphia, 1996.

SCHERRE, M. M. P.; YACOVENCO, L. C.; SCARDUA, J. R. A Alternância tu e você: Cartas Capixabas. Revista Confluência- Instituto de Língua Portuguesa, $\mathrm{n}^{\mathrm{o}}$ 54. Rio de janeiro, 2018, p. 9-25.

SILVA, M. R. da, Tu e você na variedade rio-branquense: Um caso de variação ou de escolha funcional? 2019. 178f. Tese (Doutorado em Estudos Linguísticos). Instituto de Biociências, Letras e Ciências Exatas, Universidade Estadual Paulista, São José do Rio Preto.

STEVENS, James P. Applied Multivariate Statistics for the Social Sciences. New York: Routledge, 2015. 
VASSOLER, L.; CAMACHO, R.G. crenças e atitudes linguísticas: a variante retroflexa na variedade rio-pretense Revista do GEL, São Paulo, v. 13, n. 2, p. 163-191, 2016. 